\title{
MEMBANGUN E-COMMERCE UNTUK MASTER DEALER ASESORIS KOMPUTER CV.TRANSMIT.NET TANJUNGSARI SUMEDANG
}

\author{
Albert Andreas Yohannes ${ }^{1}$, Linda Salma Angrezni ${ }^{2}$ \\ ${ }^{1}$ PT. Finnet-Indonesia, ${ }^{2}$ Teknik Informatika UIN Maulana Malik Ibrahim Malang, \\ andreasaint@gmail.com, lindasalma@gmail.com
}

\begin{abstract}
ABSTRAK
Bagian pemasaran menjadi kebutuhan yang sangat penting dikarenakan banyaknya keuntungan dan nafas dari sebuah bisnis adalah mutlak tergantung dari suksesnya bagian pemasaran dalam bisnis digelutinya sehingga perlu untuk mengangkat masalah bidang pemasaran dengan lebih spesifik adalah promosi bidang usaha dan penjualan produk secara online (ecommerce).Lokasi penelitian adalah Toko Komputer Transmit.net Tanjungsari Sumedang sedangkan software untuk membangun aplikasi e-commerce menggunakan web server Apache 2.2.6, script PHP 5.2.5, database MySQL 5.0.51. Implementasi aplikasi web Transmit.net $e$ commerce telah di upload ke internet dengan alamat url: www.tmi-net.com berfungsi sesuai seperti pada localhost dan juga masih terdapat banyak kekurangan dan kelemahan pada aplikasi web Transmit.net e-commerce yang dapat disempurnakan pada penelitian di masa datang.
\end{abstract}

Kata Kunci : E-commerce, ww.tmi-net.com, Transmit.net Tanjungsari, MySql.

\section{PENDAHULUAN}

Perkembangan internet menyebabkan setiap individu memiliki hak dan kemampuan untuk berinteraksi dengan individu lainnya. Sektor bisnis merupakan sektor yang paling terkena dampak dari perkembangan dari teknologi informasi dan telekomunikasi. Melalui ecommerce dapat memiliki peluang yang sama agar dapat bersaing dan berhasil didunia maya. CV.Transmit.Net adalah sebuah master dealer untuk asesoris computer yang berlokasi di jalan karangsari no.1 tajungsari sumedang. Transmit dalam proses transaksinya memiliki cukup banyak pelanggan dalam cakupan wilayah sekitar tanjungsari maupun luar wilayah sumedang. Hal tersebut menyebabkan Transmit mengalami kesulitan dalam melakukan transaksi jarak jauh dengan para pelanggan yang berada di luar wilayah tanjungsari sumedang.

Dalam proses penyampaian informasi kepada pelanggan masih mengalami kesulitan mengenai produk-produk apa saja yang ada serta koleksi produk-produk yang terbaru yang ada di Transmit, dalam hal penyajian informasi ini masih dilakukan secara konvensional yaitu dengan mencetak brosur untuk mempublikasikan hal tersebut dimana brosur tersebut dibagikan kepada konsumen dan display di Transmit, sehingga daya beli konsumen terbatas dan adanya biaya ekstra yang cukup besar untuk mempublikasikan bila adanya perubahan informasi dari sisi produk ataupun informasi lainnya dari transmit

Solusi yang tepat untuk menanggulangi kendala yang dihadapi Transmit.net Tanjungsari adalah pembuatan aplikasi web berbasis e-commerce. Dimana solusi yang ditawarkan adalah penerapan sistem penjualan secara online dengan menggunakan jasa internet, penerapan sistem pembayaran secara online dengan bekerjasama menggunakan jasa paypal, penerapan cara melakukan penjualan produk-produk secara online yang terintegrasi dengan Facebook (Social Networking).

Dengan diadakannya pembuatan web berbasis e-commerce tersebutdiharapkan dapat meningkatkan perluasan pemasaran lebih cepat dan dapat memberikan solusi yang lebih. Karena seluruh komponen yang 
terlibat dalam bisnis praktis diaplikasikan disini, seperti customer service, produk yang tersedia, cara pembayaran, jaminan atas produk yang dijual dan sebagainya. Seluruh definisi yang dijelaskan di atas pada dasarnya memiliki kesamaan yang mencakup komponen transaksi (pembeli, penjual, barang, jasa dan informasi), subyek dan obyek yang terlibat, serta media yang digunakan (dalam hal ini adalah internet).

Dengan menggunakan teknologi informasi, e-commerce dapat dijadikan sebagai solusi untuk membantu perusahaan dalam mengembangkan perusahaan dan menghadapi tekanan bisnis. Tingginya tekanan bisnis yang muncul akibat tingginya tingkat persaingan mengharuskan perusahaan untuk dapat memberikan respon. Penggunaan e-commerce dapat meningkatkan efisiensi biaya dan produktifitas perusahaan, sehingga dapat meningkatkan kemampuan perusahaan dalam bersaing.

\section{MODEL, ANALISIS, DESAIN, DAN IMPLEMENTASI}

\subsection{MODEL}

Teknik analisis data dalam pembuatan perangkat lunak menggunakan pemodelan perangkat lunak dengan metodewaterfall, yang meliputi beberapa proses diantaranya: a. Pengumpulan data

Pengumpulan data adalah tahappertama dalam penelitian untuk membuat sebuat software yang akan digunakan. Pengumpulan data dilakukan dengan cara melihat dan mengumpulkan data yang ada pada tempat penelitian serta melakukan wawancara dengan pihak pemilik perusahaan agar dapat dianalisa akan kebutuhan untuk software yang akan dibangun.

\section{b. Analisa Kebutuhan}

Analisa kebutuhan merupakan tahap yang menjadi dasar proses pembuatan Tailormade software selanjutnya. Kelancaran proses pembuatan software secara keseluruhan dan kelengkapan fitur software yang dihasilkan sangat tergantung pada hasil analisa kebutuhan ini.

\section{c. Design System}

Desain sistem merupakan tahap penyusunan proses, data, aliran proses dan hubungan antar data yang paling optimal untuk menjalankan proses bisnis dan memenuhi kebutuhan perusahaan sesuai dengan hasil analisa kebutuhan.

\section{d. Coding}

Penulisan kode program merupakan tahap penerjemahan desain sistem yang telah dibuat ke dalam bentuk perintah-perintah yang dimengerti komputer dengan mempergunakan bahasa pemrograman, PHP dan database MySQL yang menjadi standarisasi perusahaan untuk aplikasi internal.

\section{e. Pengujian Program}

Pengujian software dilakukan untuk memastikan bahwa software yang dibuat telah sesuai dengan desainnya dan semua fungsi dapat dipergunakan dengan baik tanpa ada kesalahan.

\section{f. Penerapan program.}

Penerapan program merupakan tahap dimana penyusun menerapkan / menginstall software yang telah selesai dibuat dan diuji ke dalam lingkungan Teknologi Informasi perusahaan dan memberikan pelatihan kepada pengguna di perusahaan.

\subsection{ANALISIS \\ 2.2.1 ANALISIS PROSEDUR YANG SEDANG BERJALAN}

Berdasarkan hasil penelitian, terdapat beberapa prosedur yang dilakukanoleh pihak toko Transmit.net Tanjungsari diantaranya:

1. Alur proses penjualan

2. Alur proses pembuatan laporan hasil penjualan

Berdasarkan hasil evaluasi sistem yang berjalan, solusi yang ditawarkan adalah pembuatan e-commerce pada toko Transmit.net Tanjungsari. Dalam sistem ini, customer dapat melihat informasi produk dan dapat melakukan pemesanan secara online. Dengan sistem ini juga diharapkan dapat membantu perusahaan dalam mempromosikan produk Transmit.net Tanjungsari serta diharapkan dapat membantu menyelesaikan pengelolaan transaksi dan pengolahan data yang terjadi di Transmit.net Tanjungsari dengan tujuan menghasilkan informasi dengan cepat dan akurat.

Solusi yang diajukan yaitu dengan membangun e-commerce untuk mengatasi permasalahan tersebut.

\subsubsection{ANALISIS KEBUTUHAN FUNGSIONAL}

\subsubsection{DIAGRAM CONTEXT}

Diagram Context merupakan alat untuk struktur analisis. Pendekatan struktur ini 
untuk menggambarkan sistem secara garis besar atau secara keseluruhan.

Diagram Context situs e-commerce di Transmit.net Tanjungsaridapat dilihat pada Gambar 1.

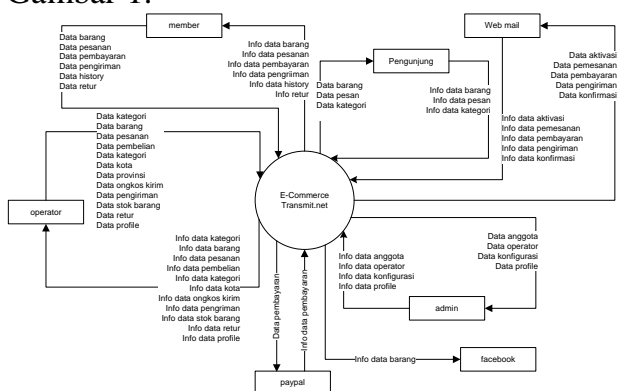

Gambar 1.Diagram

Contexttoko

Transmit.net Tanjungsari

\subsubsection{DFD Level 1}

DFD level 1 untuk situs e-commerce pada toko Transmit.net dilihatpada Gambar 2.

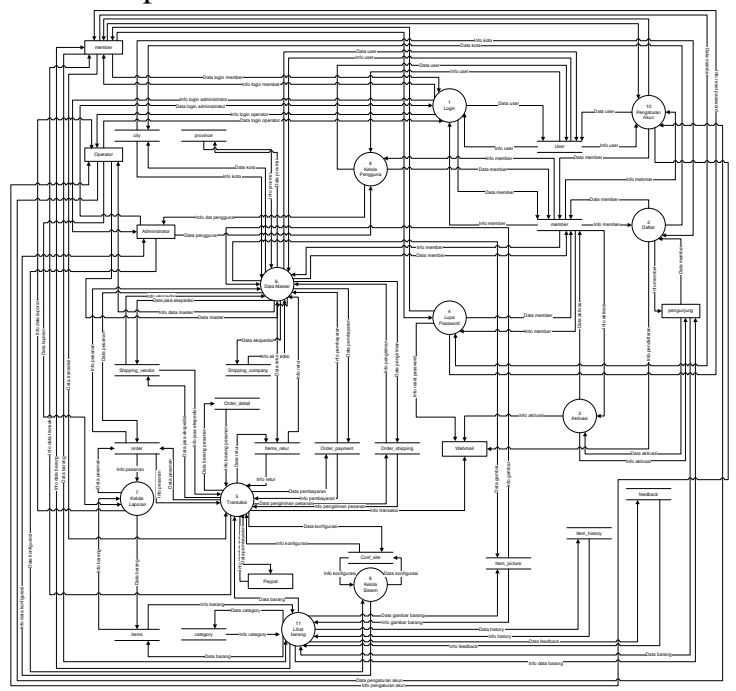

Gambar 2.DFD Level 1Aplikasi Penjualan Transmit.net Tanjungsari

\subsubsection{SKEMA RELASI}

Skema relasi dari situs e-commerce pada toko transmitdapat dilihat pada Gambar 3.

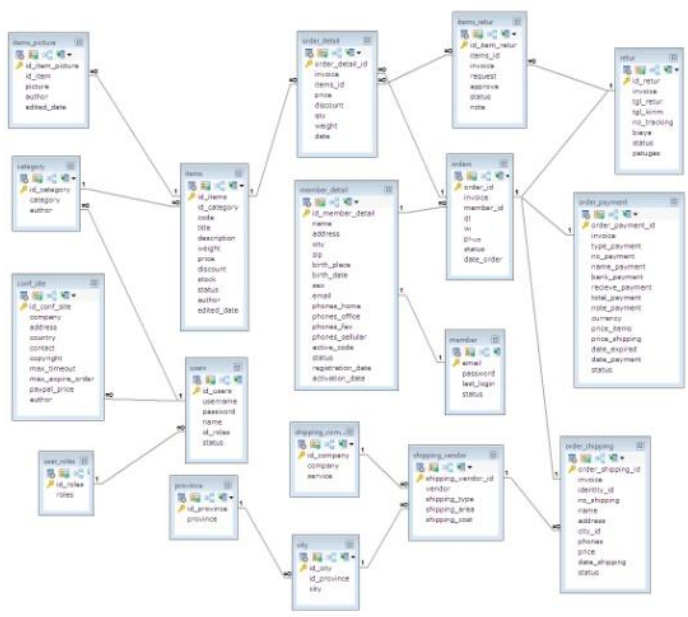

Gambar 3. Skema Relasi Basis Data pada toko Transmit.net Tanjungsari

\subsection{DESAIN}

Desain struktur menu merupakan jalur pemakaian sistem yang mudah dipahami dan mudah digunakan. Perancangan struktur menu dari situs e-commerce Transmit.net Tanjungsaridibagi menjadi tiga :

a. Struktur menu pengunjung dapat dilihat pada Gambar 4.

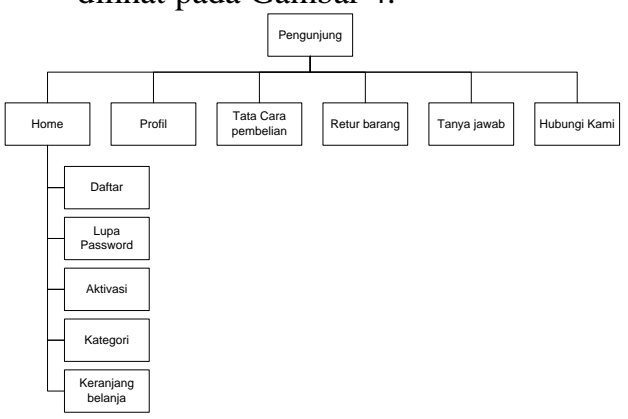

Gambar 4.Struktur Menu Pengunjung

b. Struktur menu customerdapat dilihat pada Gambar 5.

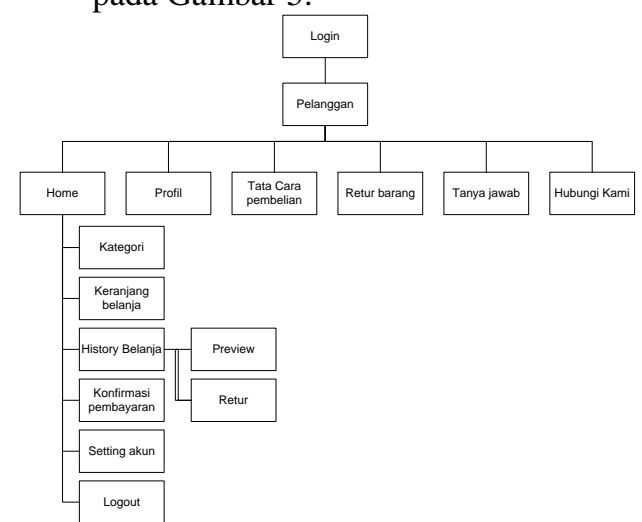

Gambar 5. Struktur Menu customer

c. Struktur menu administrator dapat dilihat pada Gambar 6 . 


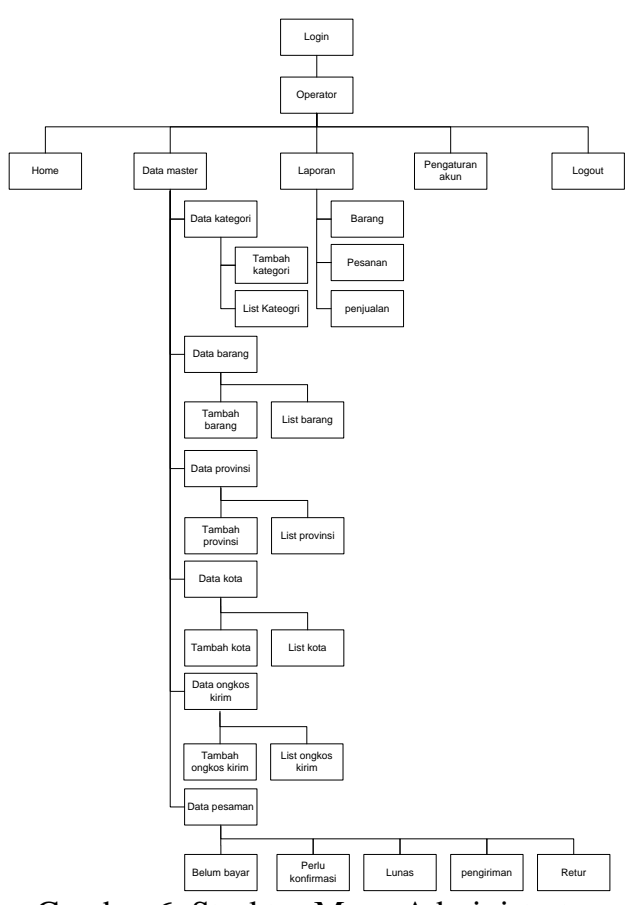

Gambar 6. Struktur Menu Administrator

\subsection{IMPLEMENTASI}

Rencana pengujian yang akan dilakukan dengan menguji sistem secara alpha dan beta.

Berdasarkan hasi pengujian alpha (fungsional) dengan kasus uji diatas dapat ditarik kesimpulan bahwa pembuatan ecommerce pada toko Transmit.net Tanjungsari bebas kesalahan penulisan dan secara fungsional mengeluarkan hasil yang sesuai dengan yang diharapkan.

Dari pengujian beta dapat ditarik kesimpulan, yaitu aplikasi sangat memudahkan pengguna dalam melakukan pencarian produk, aplikasi menggunakan bahasa yang mudah dimengerti, aplikasi memudahkan pengunjung untuk registrasi, tampilan aplikasi cukup menarik bagi pengunjung/customer, aplikasi telah menyediakan fitur-fitur yang dibutuhkan oleh pengguna, aplikasi memudahkan customer dalam hal konfirmasi pemesanan, pembayaran dan pengiriman, aplikasi memberikan customer kepuasan dalam melakukan pembelian, pengolahan data produk pada aplikasi sesuai dengan katalog produk yang ada, aplikasi memudahkan admin dalam pengelolaan data produk, data stok produk, pesanan dan retur, aplikasi mudah dipelajari dan digunakan oleh admin, aplikasi telah membantu admin dalam pembuatan dan cetak laporan, aplikasi telah membantu admin dalam memasarkan produk-produk.

\section{HASIL DAN DISKUSI}

Dari analisa dan perancangan yang telahdilakukan, hasil dari aplikasi yangdibangun salah satunya dapat terlihatseperti pada Gambar 7. dibawah ini:

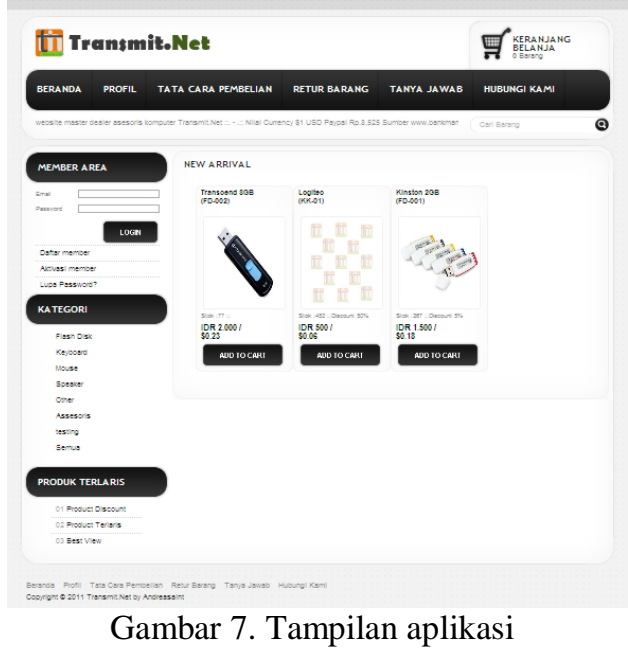

\section{KESIMPULAN DAN SARAN}

\subsection{KESIMPULAN}

Berdasarkan hasil yang didapat dalam pembuatanskripsi ini, maka dapat ditarik kesimpulan sebagai berikut :

1. Aplikasi yang dibuat sudah menggunakan transaksi online yang aman dengan menerapkan security yang baik.

2. Aplikasi yang dibuat sudah memenuhi kriteria sebagai aplikasi yang berbasis $e$ commerce.

3. Aplikasi yang dibuat memenuhi kriteria sebagai aplikasi yang User Friendly/mudah digunakan.

\subsection{SARAN}

Saran-saran terhadap penggunaan sistem yang telah dibuat adalah sebagai berikut :

1. Perlu ditingkatkan cara pembuatan aplikasi yang user friendly/mudah digunakan.

2. Perlu ditingkatkan lagi dalam segi security/keamanan pada aplikasi.

3. Perlu ditambahkan lagi fitur-fitur $e$ commerceuntuk metode pembayaran online agar tidak terpatok hanya pada satu metode saja.

\section{DAFTAR PUSTAKA}

[1] Abdul Kadir, (2000), Konsep dan Tuntunan Praktis Basis Data, Andi, Yogyakarta.

[2] Bunafit Nugroho, (2004), Aplikasi Pemograman Web Dinamis dengan $P H P$ dan MYSQL, Gava Media. 
[3] Colin McCormack, Jones David, Building A Web Based Education System, John Wiley dan Sons, New York, USA.

[4] Dafid Odang, Berbisnis Lewat Internet Dengan Paypal, Yogyakarta : Mediakom, 2009.

[5] Nofie Iman, Mengenal E-Commerce, http://www.nofieiman.com, diakses tanggal 20 maret 2010.

[6] Fathansyah, (2007), Basis Data, Informatika, Bandung.

[7] Irawan, Budhi, (2005), Jaringan Komputer, Graha Ilmu, Yogyakarta.

[8] Kadir, Abdul, (2002), Dasar Pemograman WEB Dinamis Menggunakan PHP, Andi, Yogyakarta.

[9] Prasetyo, Didik Dwi, (2005), Solusi Menjadi Web Master Melalui Manajemen Web Dengan Php, PT Elex Media Komputindo, Jakarta. 